\title{
De novo ocular hypertension after Descemet stripping endothelial keratoplasty: comparative 3-year incidence, risk factors, and outcomes
}

This article was published in the following Dove Press journal:

Clinical Ophthalmology

17 September 2013

Number of times this article has been viewed

\author{
Errol W Chan' \\ Tina T Wong ${ }^{2,3}$ \\ Hla $M \mathrm{Htoon}^{3}$ \\ Ching $\mathrm{L} \mathrm{Ho}^{2}$ \\ Donald T Tan ${ }^{1,2,3}$ \\ Jodhbir S Mehta ${ }^{2,3,4}$ \\ 'Department of Ophthalmology, \\ National University Health System, \\ Singapore; ${ }^{2}$ Singapore National \\ Eye Centre, Singapore; ${ }^{3}$ Singapore \\ Eye Research Institute, Singapore; \\ ${ }^{4}$ Department of Clinical Sciences, \\ Duke-NUS Graduate Medical School, \\ Singapore
}

Objective: To compare the 3-year incidence of de novo ocular hypertension (OHT) after Descemet stripping automated endothelial keratoplasty (DSAEK) and penetrating keratoplasty (PK). For DSAEK, to evaluate predictors for OHT and 2-year outcomes after OHT development.

Methods: This was a review of the prospective Singapore Corneal Transplant Study at a single tertiary referral center. Consecutive DSAEKs and PKs for Fuchs' endothelial dystrophy (FED) and pseudophakic bullous keratopathy (PBK) in eyes without pre-existing glaucoma were analyzed. OHT incidence after DSAEK and PK were compared using Kaplan-Meier survival analysis, and OHT risk factors identified using Cox proportional regression. OHT was defined: intraocular pressure (IOP) $\geq 24 \mathrm{mmHg}$ or $\geq 10 \mathrm{mmHg}$ from baseline. Secondary outcomes 2 years after OHT development in DSAEK were rates of glaucoma medical therapy failure, IOP success, graft failure and rejection, and best-spectacle corrected visual acuity (BSCVA).

Results: There were 108 (96.4\%) DSAEKs and 216 (96\%) PKs. The 1-, 2- and 3-year de novo OHT incidence was not significantly different between DSAEK $(36.1 \%, 47.2 \%, 47.2 \%$, respectively) and PK (35.7\%, 44.9\%, 45.8\%, respectively; $P=0.914)$. OHT incidence did not differ in subgroup analyses of multiple clinical variables $(P>0.1)$. OHT predictors after DSAEK were: fellow eye glaucoma (hazard ratio [HR] 3.20, $P=0.004$ ), age $<60$ years (HR 2.41, $P=0.016$ ), concurrent goniosynechiolysis (HR 3.29, $P=0.021$ ), post-graft complications or procedures (HR 2.85, $P=0.006$ ). Two years after OHT onset, 29.7\% of DSAEKs failed glaucoma medical therapy requiring trabeculectomy. Complete and qualified IOP success was achieved in $23.5 \%$ and $76.5 \%$, respectively. Graft failure developed in $9.8 \%$ and graft rejection in $5.9 \%$. At 6 months, 1 , and 2 years from OHT onset, $86.3 \%, 88.3 \%$, and $92.1 \%$ achieved BSCVA 20/40, respectively.

Conclusion: DSAEK and PK have comparable OHT risks. A significant 30\% of DSAEK eyes with OHT require filtration surgery. Effective IOP control and good graft and visual outcomes are achieved with treatment.

Keywords: DSAEK, glaucoma, ocular hypertension, risk factors

\section{Introduction}

Descemet stripping automated endothelial keratoplasty (DSAEK) has emerged as the standard of care for corneal endothelial dysfunction. Compared to penetrating keratoplasty (PK), DSAEK has earlier and predictable visual recovery, less ocular surface complications, and superior tectonic safety. ${ }^{1-3}$

Initial expectations were that DSAEK would offer lower risks of post-graft ocular hypertension (OHT) than PK, due to absence of graft-host disparity or suture-induced angle distortion. Post-PK OHT is a significant complication as it leads to graft failure,
Correspondence: Jodhbir S Mehta Singapore National Eye Centre and Singapore Eye Research Institute, II Third Hospital Avenue, 16875I Singapore

Email jodmehta@gmail.com 
endothelial cell loss, and poor visual outcomes. ${ }^{4,5}$ However, the incidence of post-DSAEK OHT is reported to occur between $35 \%$ and $43 \%$. $^{6-11}$

Several areas of uncertainty exist. First, although an earlier report found that $35 \%$ of DSAEK eyes with no preexisting glaucoma developed OHT at 1-year (ie, de novo OHT), ${ }^{6}$ the comparative medium-term (ie, 3-year) OHT incidence after DSAEK and PK is unknown. A prospective randomized trial would be the most ideal comparative method, but this is ethically unjustifiable as DSAEK has clearly superior short-term visual outcomes. An acceptable method would be a single-center analysis, using standardized OHT diagnostic criteria, intraocular pressure (IOP), and corneal thickness measurement techniques, and steroid regimens. Second, predisposing factors for OHT after DSAEK are unknown. Third, studies have largely focused on IOP elevation in eyes with pre-existing glaucoma, and Fuchs' endothelial dystrophy (FED); ${ }^{6-11}$ with limited data for de novo OHT, or pseudophakic bullous keratopathy (PBK). Finally, a comprehensive evaluation of intermediate-term IOP and graft outcomes after DSAEK are unknown.

The aims of this study were to: (1) compare the incidence of de novo post-graft OHT between DSAEK and PK within 3 years, (2) evaluate risk factors for OHT after DSAEK, and (3) determine 1-year outcomes (failure of medical therapy, IOP success, visual acuity, and graft survival) after OHT development.

\section{Patients and methods Inclusion and exclusion criteria}

A retrospective review was performed of DSAEK and PK grafts from the Singapore Corneal Transplant Study (SCTS). The SCTS is an ongoing long-term prospective study of corneal grafts at the Singapore National Eye Centre, a tertiary referral center for corneal diseases for $>90 \%$ of transplants in Singapore. ${ }^{12}$ This study received Singhealth Institutional Board approval.

We included all cases expected to have 3 years follow-up at review in January 2013; ie, cases performed up to January 2010. Therefore, of 250 consecutive DSAEKs performed from January 2, 2006 to January 3, 2010, we selected eyes with FED and PBK. We also reviewed consecutive PK grafts from March 5, 2005 to January 7, 2010, and identified eyes with FED or PBK. We specifically included recent PK cases to minimize temporal bias, however the slightly earlier eligibility period for PKs was due to DSAEKs being increasingly performed for endothelial dysfunction. We excluded eyes with pre-existing glaucoma or other surgical indications ie, regrafts, laser-induced bullous keratopathy, or iridocorneal endothelial syndrome. The first eye was included in patients with bilateral grafts.

Eyes with no pre-existing glaucoma were defined based on the European Glaucoma Society Guidelines and by Vajaranant et al: ${ }^{6,13}$ (1) no IOP of $>21 \mathrm{mmHg}$, and no topical or systemic IOP-lowering medication use, (2) no glaucomatous optic neuropathy (GON; cup-disc ratio $>0.6$ in the presence of a glaucomatous visual field defect, focal neuroretinal rim defects), (3) no previous laser peripheral iridotomy, iridoplasty, cyclodestructive, or filtration procedures, and (4) no documented history of glaucoma.

\section{Preoperative evaluation}

All patients underwent a comprehensive ophthalmic examination including best-spectacle corrected (BSCVA) Snellen visual acuity testing, gonioscopy, anterior and dilated posterior segment evaluation including stereoscopic optic disc assessment with a 78-D lens (Volk Optical Inc, Mentor, OH, USA), and IOP measurement while undilated with Goldmann appalanation tonometry (GAT, Haag-Streit, Konig, Switzerland), or TonopenXL (Reichert Inc., Depew, NY, USA) in eyes with significant stromal scarring precluding GAT measurements. Central corneal thickness (CCT) was measured with an ultrasound pachymeter (Sonogage, Cleveland, OH, USA). Automated perimetry at baseline was documented (Humphrey visual field analyzer II, SITA 24-2 fast, Carl Zeiss Meditec, Dublin, CA, USA).

\section{Operative technique}

Five corneal surgeons (DTT, JSM, and three other surgeons) performed DSAEK according to a previously described standardized technique. ${ }^{14,15}$ A donor lamellar dissection was achieved with a Moria automated lamellar therapeutic keratoplasty (ALTK) microkeratome (Moria USA, Doylestown, PA, USA), and donor trephination performed using a standard Hanna punch system with trephine sizes between $7.75 \mathrm{~mm}$ and $9 \mathrm{~mm}$ in $0.25 \mathrm{~mm}$ increments. A $5 \mathrm{~mm}$ scleral tunnel was created. Descemet's stripping was performed under air ${ }^{14}$ and the graft inserted using the Sheets-glide technique. A surgical iridectomy was performed in all cases. Interface fluid was drained through paracentral venting incisions. An air bubble was injected into the anterior chamber to oppose the graft to the host cornea, but partially evacuated to a size approximating the dimensions of the graft before the end of surgery.

PK grafts were performed by nine corneal surgeons, including the aforementioned five surgeons. The Hanna punch trephine was used to cut 0.25 to $0.50 \mathrm{~mm}$ oversized donor buttons. A Hanna suction trephine centered on the 
geometric center of the recipient cornea was used to cut a circular, partial depth incision in the recipient, and the remaining cornea excised. The donor was sutured with either an 8-bite 10-0 nylon double continuous running suture or a combination of single 8-bite 10-0 nylon continuous and eight interrupted sutures.

For DSAEK, concurrent surgeries (eg, cataract extraction, goniosynechiolysis, anterior chamber intraocular lens [ACIOL] exchange, vitrectomy) were performed before donor insertion. ACIOLs were exchanged or scleral-fixated IOLs were implanted. For PK, concurrent surgeries were performed before excision of the recipient cornea.

\section{Postoperative evaluation and management}

Follow-up examinations were performed on the 1 st and 5 th postoperative day, 2nd postoperative week, and 1-, 2-, 3-, 6-, 9-, and 12-, 18-, 24-, and 36-month intervals. Further visits were scheduled where clinically indicated. A postoperative clinical evaluation was performed as for the preoperative visit, including BSCVA, anterior and posterior segment evaluation, undilated IOP measurement with GAT in all cases other than those with high astigmatism or corneal edema, where Tonopen was used, and CCT measurement. All DSAEK and PK grafts received daily 3-hourly topical prednisolone acetate 1\% (Pred Forte ${ }^{\circledR}$, Allergan, Irvine, CA, USA) for the first 7 days, tapering to 4, 3, 2, and 1-times a day by $1,3,6$, and 12 months, respectively.

DSAEK cases with OHT were managed by two glaucoma fellowship-trained specialists (TTW and CLH). Topical IOP-lowering medications were instituted as the initial treatment for all cases. For OHT cases judged to be at low risk for graft rejection, prednisolone acetate $1 \%$ was substituted with fluorometholone $0.25 \%$ (FML, Allergan) or loteprednol etabonate $0.5 \%$ (Lotemax, Bausch and Lomb, Rochester, NY, USA) at the same frequency. Visual field testing was conducted at 6-monthly intervals from OHT onset.

\section{Definition of post-graft ocular hypertension}

Post-graft OHT was defined as IOP $\geq 24 \mathrm{mmHg}$ or $\geq 10 \mathrm{mmHg}$ increase at any postoperative examination, consistent with an earlier study. ${ }^{6}$

\section{Glaucoma medical therapy failure, IOP success, and graft failure}

Outcomes of OHT in DSAEK eyes were assessed at 2 years after OHT onset. The primary outcomes were failure of medical therapy and IOP. A mitomycin-C-augmented trabeculectomy was indicated when IOP was $>21 \mathrm{mmHg}$ on two consecutive visits, despite maximum medical therapy. Complete IOP success was defined as IOP $<22 \mathrm{mmHg}$, and qualified IOP success as IOP $<22 \mathrm{mmHg}$ on medications.

Secondary outcomes were graft failure and rejection, and BSCVA. Graft failure was defined as irreversible corneal edema with increased corneal thickness $\geq 2$ months; graft wrinkles causing reduced VA were not considered graft failures as endothelial reserve was considered healthy. Graft rejection was defined by an epithelial rejection line, subepithelial infiltrates, stromal rejection with Krachmer's spots, anterior chamber cells, keratic precipitates, or an endothelial rejection line, with or without concomitant corneal edema.

\section{Statistical analysis}

Quantitative variables were compared with two-sample Student $t$-tests, and categorical variables using chi-square tests. The proportions of DSAEK and PK grafts developing OHT through 3 years were compared using Kaplan-Meier survival analysis and the log-rank test. To address potential systematic errors of different IOP measurement techniques and corneal edema, the survival analysis was repeated only in eyes with pre- or post-graft GAT measurements and clear post-graft corneas. As OHT risk could depend on various clinical characteristics (Table 1), Cox proportional regression was used to systematically assess individual associations between OHT and the interaction term of each factor with graft type (DSAEK/PK).

Cox regression was also performed to analyze ten potential post-DSAEK OHT risk factors (Table 2). Statistically significant variables in the univariate analysis were included in multivariate models. The fit of the multivariate model was evaluated using the $R^{2}$ statistic, indicating the proportion of variance in 3-year OHT incidence explained by the statistically significant factors. All tests were two-tailed, and $P<0.05$ was considered statistically significant. Statistical analyses were performed with STATA 12.1 (StataCorp LP, College Station, TX, USA).

\section{Results \\ Characteristics}

There were 112 DSAEKs and 225 PKs. After excluding 4 DSAEKs and 9 PKs with $<3$ years of follow-up, 108 DSAEKs and 216 PKs were analyzed. DSAEK and PK cohorts were comparable for age $(66.2 \pm 12.1$ versus $67.1 \pm 12.3$ years), gender (male, $47.2 \%$ versus $46.3 \%$ ), surgical indication (FED, 47.2\% versus $47.2 \%$ ), phakic 
Table I Demographic, pre-, intra-, and postoperative characteristics of Descemet stripping automated endothelial keratoplasty and penetrating keratoplasty eyes

\begin{tabular}{|c|c|c|c|}
\hline & $\begin{array}{l}\text { DSAEK }(n=108) \\
n(\%)\end{array}$ & $\begin{array}{l}\text { PK (n = 2I } 6) \\
n(\%)\end{array}$ & $P$-value \\
\hline Recipient age in years & $66.2 \pm 12.1$ & $67.1 \pm 12.3$ & 0.546 \\
\hline Gender & & & 0.875 \\
\hline Male & $51(47.2)$ & $100(46.3)$ & - \\
\hline Female & $57(52.8)$ & $116(53.7)$ & - \\
\hline Ethnicity & & & 0.023 \\
\hline Chinese & $73(67.6)$ & I7I (79.2) & - \\
\hline Non-Chinese & $35(32.4)$ & $45(20.8)$ & - \\
\hline Pre-graft IOP in mmHg (mean $\pm S D$ ) & $12.9(3.5)$ & $14.2(3.9)$ & 0.002 \\
\hline Pre-graft CCT in $\mu \mathrm{m}($ mean $\pm \mathrm{SD})$ & $687.7(92.1)$ & $667.8(140.3)$ & 0.130 \\
\hline Surgical indication & & & 1.000 \\
\hline FED & $51(47.2)$ & $102(47.2)$ & - \\
\hline PBK & $57(52.8)$ & II 4 (52.8) & - \\
\hline Pre-graft phakic status & & & 0.090 \\
\hline Pseudophakic & $86(79.6)$ & $153(70.8)$ & - \\
\hline Phakic & $22(20.4)$ & $63(29.2)$ & - \\
\hline DSAEK graft diameter in mm (mean \pm SD) & $8.67(0.44)$ & - & - \\
\hline PK graft & & & - \\
\hline Donor diameter in mm (mean $\pm \mathrm{SD})$ & - & $7.88(0.35)$ & - \\
\hline Recipient diameter in mm (mean \pm SD) & - & $7.54(0.87)$ & - \\
\hline \multicolumn{4}{|l|}{ Surgeon experience with procedure } \\
\hline$>5$ years & $4(0.80)$ & $8(0.89)$ & - \\
\hline$\leq 5$ years & I $(0.20)$ & $\mathrm{I}(0.1 \mathrm{I})$ & 1.00 \\
\hline Concurrent procedures & & & $<0.001$ \\
\hline Stand-alone DSAEK/PK & $79(73.2)$ & $107(49.5)$ & - \\
\hline DSAEK/PK with cataract extraction and intraocular lens implantation & $22(20.4)$ & $63(29.2)$ & - \\
\hline $\begin{array}{l}\text { DSAEK/PK with goniosynechiolysis (with or without ACIOL exchange } \\
\text { or anterior vitrectomy)*** }\end{array}$ & $7(6.5)^{*}$ & $46(21.3)^{* *}$ & - \\
\hline Postoperative procedures ${ }^{\dagger, t \dagger}$ or complications $s^{\alpha, \beta}$ & & & 0.207 \\
\hline No & $97(89.8)$ & $183(84.7)$ & - \\
\hline Yes & II $(10.2)^{\dagger, \alpha}$ & $33(15.3)^{\dagger+\beta}$ & - \\
\hline Post-graft CCT in $\mu \mathrm{m}$ (mean $\pm \mathrm{SD})$ & $675.0(125.3)$ & $658.8(102.0)$ & 0.888 \\
\hline
\end{tabular}

Notes: *Goniosynechiolysis alone (five cases), goniosynechiolysis with ACIOL exchange (one case), goniosynechiolysis with anterior vitrectomy (one case); **goniosynechiolysis alone (35 cases), goniosynechiolysis with ACIOL exchange (seven cases), goniosynechiolysis with anterior vitrectomy (four cases); ${ }^{\dagger}$ postoperative procedures for DSAEK: graft repositioning (three cases), YAG capsulotomy (three cases), and scleral buckling (one case); ${ }^{\dagger}$ postoperative procedures for PK: resuturing of graft dehiscence (ten cases), anterior chamber washout (two cases), YAG capsulotomy (two cases), pars plana vitrectomy for dropped IOL (one case), scleral-fixation of IOL (one case); ${ }^{\alpha}$ postoperative complications for DSAEK: graft dislocation (three cases), CMV endothelitis (one case), herpes simplex keratouveitis (one case), microsporidial keratitis (one case),

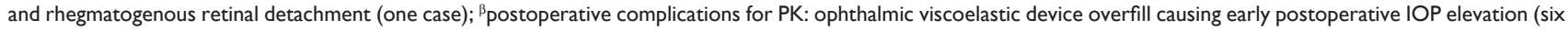
cases), infective keratitis (seven cases, four with hypopyon), endophthalmitis (one case), early postoperative hyphema (one case), traumatic wound dehiscence (ten cases), graft rejection (one case), choroidal effusion (one case).

Abbreviations: ACIOL, anterior chamber intraocular lens; CCT, central corneal thickness; DSAEK, Descemet stripping automated endothelial keratoplasty; FED, Fuchs' endothelial dystrophy; IOP, intraocular pressure; PBK, pseudophakic bullous keratopathy; PK, penetrating keratoplasty; SD, standard deviation; YAG, yttrium aluminum garnet.

status (pseudophakic, $79.6 \%$ versus $70.8 \%$ ), postoperative procedures and complications $(89.8 \%$ versus $84.7 \%)$, pre- $(687.7 \pm 92.1$ versus $667.8 \pm 140.3 \mu \mathrm{m})$ and post-graft CCT $(674 \pm 125.3$ versus $658 \pm 102.0 \mu \mathrm{m} ; P>0.05$ for all; Table 1). However, the DSAEK group had less Chinese (67.6\% versus $79.2 \% ; P=0.023)$, lower pre-graft IOP (12.9 versus $14.2 \mathrm{mmHg} ; P=0.002$ ), and more stand-alone grafts (73.2\% versus $49.5 \%, P<0.001)$. Mean DSAEK graft diameter was $8.67 \pm 0.44 \mathrm{~mm}$; donor and recipient PK diameters were $7.88 \pm 0.35$ and $7.54 \pm 0.87 \mathrm{~mm}$, respectively. Details of concurrent procedures and postoperative procedures and complications are appended in Table 1.

\section{Incidence of post-graft OHT}

There were no significant differences in the cumulative probabilities of post-DSAEK and post-PK OHT at 1-year (36.1\% versus $35.7 \%), 2$ years $(47.2 \%$ versus $44.9 \%)$, and 3 years $(47.2 \%$ versus $45.8 \%$; log-rank $P=0.914$; Figure 1). The mean survival time to OHT onset was $7.7 \pm 5.4$ months after DSAEK and $7.3 \pm 6.4$ months after 
Table 2 Ocular hypertension following Descemet stripping automated endothelial keratoplasty: unadjusted Cox proportional hazard risk by demographics, diagnosis, and clinical characteristics

\begin{tabular}{|c|c|c|c|c|c|}
\hline & $\begin{array}{l}\text { No with glaucoma/ } \\
\text { no of DSAEK }\end{array}$ & $\begin{array}{l}\text { Incidence } \\
\text { rate (\%) }\end{array}$ & $\begin{array}{l}\text { Unadjusted } \\
\text { hazard ratio }\end{array}$ & $95 \% \mathrm{Cl}$ & $P$-value \\
\hline \multicolumn{6}{|l|}{ Recipient age in years } \\
\hline$\geq 70$ & $16 / 47$ & 34.0 & Reference & & \\
\hline $60-69$ & $19 / 34$ & 55.9 & $\mathrm{I} .86$ & $0.96,3.62$ & 0.067 \\
\hline$<60$ & $16 / 27$ & 59.3 & 2.15 & $\mathrm{I} .08,4.3 \mathrm{I}$ & 0.030 \\
\hline \multicolumn{6}{|l|}{ Gender } \\
\hline Female & $27 / 57$ & 47.4 & Reference & & \\
\hline Male & $24 / 51$ & 47.1 & 1.12 & $0.65,1.94$ & 0.688 \\
\hline \multicolumn{6}{|l|}{ Ethnicity } \\
\hline Non-Chinese & $16 / 35$ & 45.7 & Reference & & \\
\hline Chinese & $35 / 73$ & 47.9 & 0.97 & $0.54,1.76$ & 0.928 \\
\hline \multicolumn{6}{|l|}{ Surgical indication } \\
\hline FED & $24 / 51$ & 47.1 & Reference & & \\
\hline PBK & $27 / 57$ & 47.4 & 1.10 & $0.64,1.91$ & 0.726 \\
\hline \multicolumn{6}{|l|}{ Glaucoma in fellow eye } \\
\hline No & $43 / 98$ & 43.9 & Reference & & \\
\hline Yes & $8 / 10^{*}$ & 80.0 & 2.69 & $1.25,5.75$ & 0.011 \\
\hline \multicolumn{6}{|l|}{ Preoperative phakic status } \\
\hline Pseudophakic & $40 / 86$ & 46.5 & Reference & & \\
\hline Phakic & $1 \mathrm{I} / 22$ & 50.0 & 1.05 & $0.54,2.04$ & 0.891 \\
\hline Pre-graft IOP, per mmHg increase & - & - & 1.08 & $0.96,1.22$ & 0.193 \\
\hline DSAEK graft diameter, per $\mathrm{mm}$ increase & - & - & 1.08 & $0.56,2.10$ & 0.820 \\
\hline \multicolumn{6}{|l|}{ Concurrent procedures } \\
\hline Stand-alone DSAEK & $35 / 79$ & 44.3 & Reference & & \\
\hline DSAEK with cataract extraction and intraocular lens implantation & $1 \mathrm{I} / 22$ & 50.0 & 1.14 & $0.58,2.24$ & 0.711 \\
\hline $\begin{array}{l}\text { DSAEK with goniosynechiolysis (with or without } \mathrm{ACIOL} \text { exchange } \\
\text { or anterior vitrectomy) }\end{array}$ & $5 / 7 * *$ & 71.4 & 2.66 & $1.03,6.82$ & 0.042 \\
\hline \multicolumn{6}{|l|}{ Postoperative procedures or complications } \\
\hline No & $42 / 97$ & 43.3 & Reference & & \\
\hline Yes ${ }^{+,++}$ & $9 / 11$ & 81.8 & 2.57 & $1.25,5.29$ & 0.011 \\
\hline
\end{tabular}

Notes: *Ten fellow eyes had primary or secondary glaucoma: primary open angle glaucoma (two eyes), primary angle closure glaucoma (two eyes), post-PK glaucoma (five eyes), and rubeotic glaucoma (one eye); **Five eyes had goniosynechiolysis only, one eye had goniosynechiolysis and anterior vitrectomy, and one eye had goniosynechiolysis, anterior vitrectomy and ACIOL exchange; ${ }^{+}$postoperative procedures for DSAEK: graft repositioning (three cases), YAG capsulotomy (three cases), and scleral buckling (one case); ${ }^{++}$Post-operative complications for DSAEK: graft dislocation (three cases), CMV endothelitis (one case), herpes simplex keratouveitis (one case), microsporidial keratitis (one case), and rhegmatogenous retinal detachment (one case).

Abbreviations: $\mathrm{ACIOL}$, anterior chamber intraocular lens; $\mathrm{Cl}$, confidence interval; DSAEK, Descemet stripping automated endothelial keratoplasty; FED, Fuchs' endothelial dystrophy; IOL, intraocular lens; No, number; PBK, pseudophakic bullous keratopathy; YAG, yttrium aluminum garnet; IOP, intraocular pressure.

PK. Analyzing 93 DSAEK and 174 PK eyes with only pre- and post-graft IOP measurements by GAT and clear grafts showed comparable OHT incidence at all time points $(P=0.214)$. Ethnicity, pre-graft IOP, and concurrent procedures differed between DSAEK and PK groups, but their interactions with graft type were not associated with OHT in Cox regression $(P=0.865, P=0.162$, and $P=0.607$, respectively). In similar regression models, OHT risk was not associated with all interaction terms of graft type and each variable in Table $1(P>0.05)$.

\section{DSAEK OHT risk factors}

In univariate analyses, post-DSAEK OHT was associated with glaucoma in the fellow eye $(P=0.011)$, DSAEK grafts with goniosynechiolysis (with or without ACIOL exchange and anterior vitrectomy; $P=0.042)$, and postoperative procedures and complications $(P=0.011)$, and age $<60$ years $(P=0.03$; Table 2$)$. Other factors, including surgical indication, were not associated with OHT risk $(P>0.05)$. These four factors remained significant in the multivariate analysis (Table 3 and Figure 2A-D): glaucoma in the fellow eye (hazard ratio [HR] 3.20; 95\% confidence interval [CI], 1.46,7.05; $P=0.004)$, post-operative procedures and complications (HR 2.85; 95\% CI, 1.35,6.04; $P=0.006$ ), goniosynechiolysis (HR 3.29; 95\% CI; $1.20,9.01 ; P=0.021$ ), and age $<60$ years (HR $2.41 ; 95 \%$ CI, $1.17,4.93 ; P=0.016)$. The cumulative OHT risk at each interval is indicated in Figure 2A-D. These four factors explained $23 \%$ of variability in OHT risk in the multivariate model. 


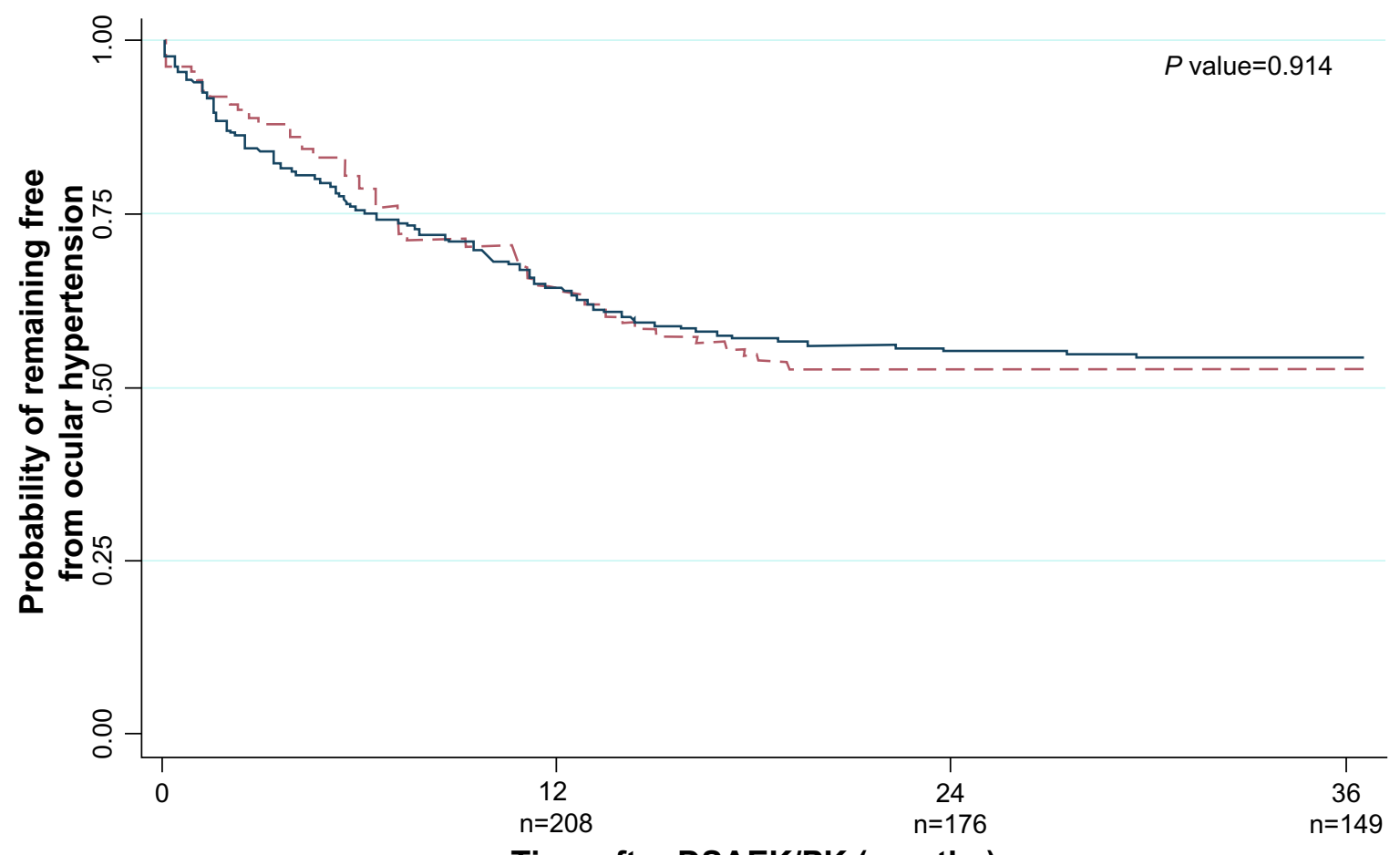

Time after DSAEK/PK (months)

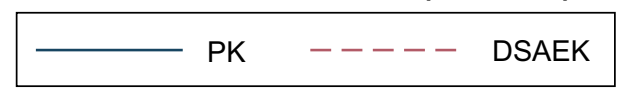

Figure I Kaplan-Meier survival curve showing probability of remaining ocular hypertension-free following Descemet stripping automated endothelial keratoplasty and penetrating keratoplasty.

Abbreviations: DSAEK, Descemet stripping automated endothelial keratoplasty; PK, penetrating keratoplasty.

Table 3 Ocular hypertension following Descemet stripping automated endothelial keratoplasty: multivariate-adjusted Cox proportional hazard risk for recipient age, fellow eye glaucoma status, concurrent procedures, and postoperative procedures or complications

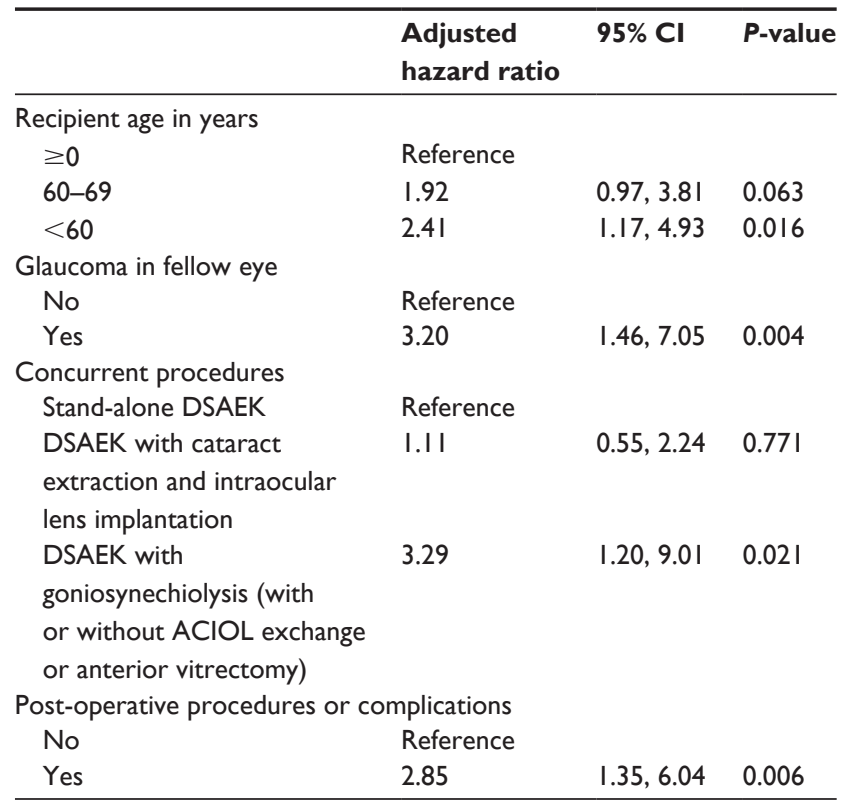

Abbreviations: $\mathrm{AClOL}$, anterior chamber intraocular lens; $\mathrm{Cl}$, confidence interval; DSAEK, Descemet stripping automated endothelial keratoplasty.

\section{IOP and graft outcomes 2 years after OHT in DSAEK}

Data on 2-year outcomes after OHT development were available for all 51 DSAEK eyes with OHT (Table 4). Switch to low-potency steroids was made in 7 DSAEK eyes (5.6\%). Failure of medical therapy requiring trabeculectomy was observed in 15 eyes (29.4\%). Complete IOP success at 2 years was achieved in 12 eyes $(23.5 \%$; all requiring trabeculectomy), and qualified IOP success in 39 eyes (76.5\%; 3 requiring trabeculectomy). The mean IOP at 2 years was $17.8 \mathrm{mmHg}$. Proportion achieving BSCVA of $20 / 40$ or better was $86.3 \%$ at 6 months, $88.3 \%$ at 1 -year, and $92.1 \%$ at 2 years. Endothelial failure occurred in $9.8 \%$, and graft rejection in $5.9 \%$.

Three post-hoc multivariate analyses were conducted to determine the impact of OHT on risk of trabeculectomy requirement, graft failure and rejection at 3 years for 108 DSAEK eyes (Supplementary Table S1). Relevant variables were included in the respective models as indicated. OHT was not associated with BSCVA, graft failure, or graft rejection outcomes $(P=0.951, P=0.489, P=0.300$, respectively). 


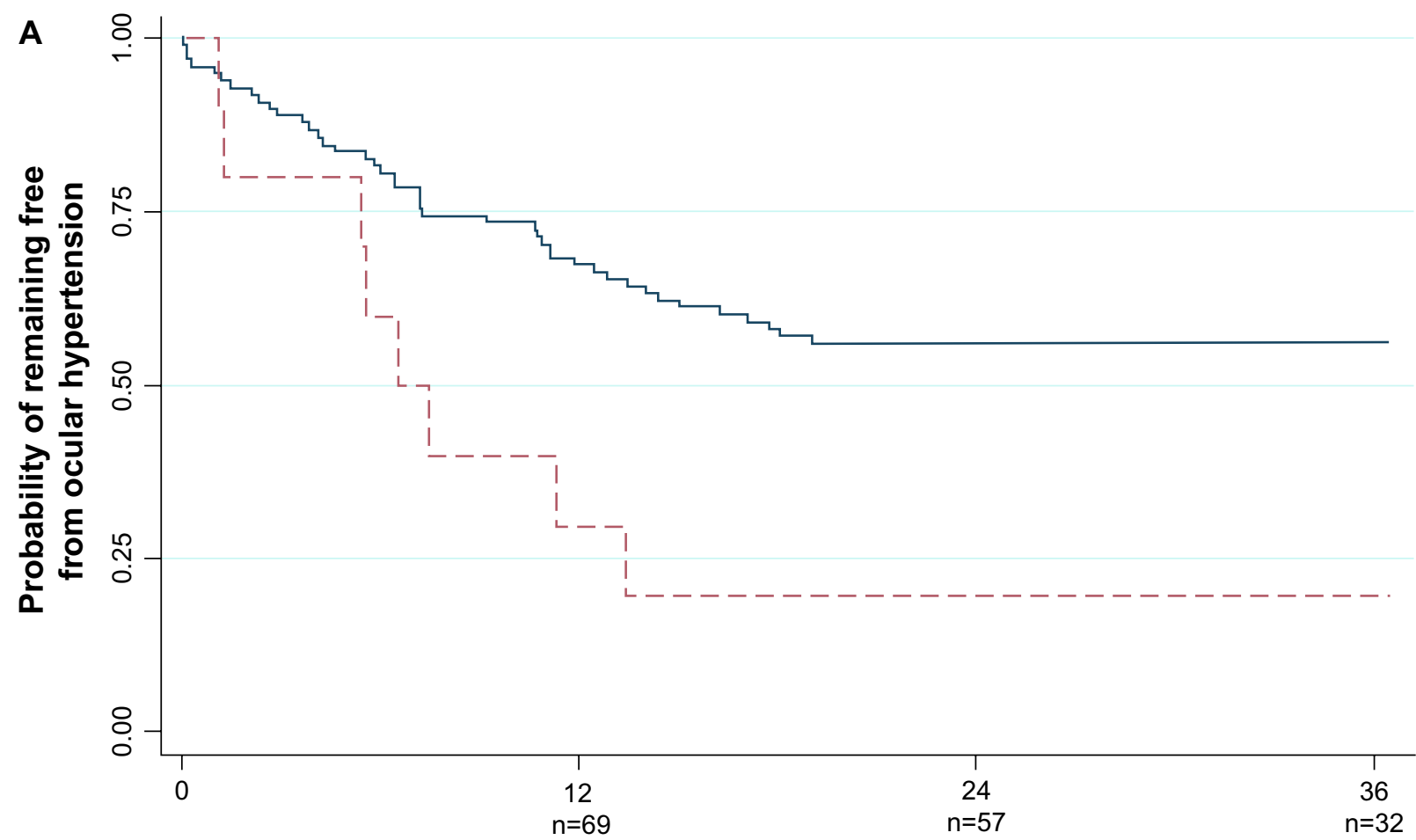

Time after DSAEK (months)

----- Glaucoma in fellow eye $\quad$ No glaucoma in fellow eye

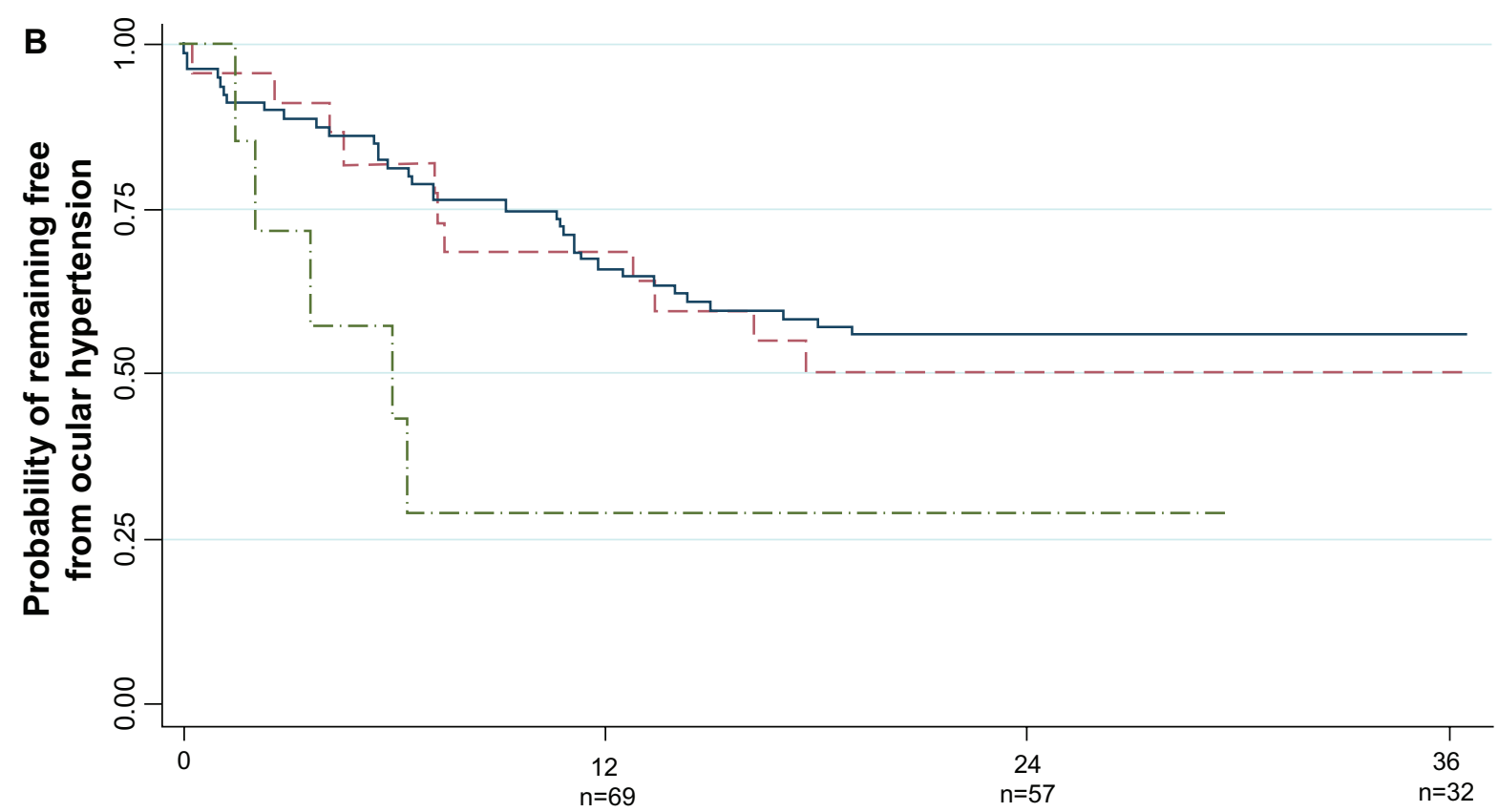

Time after DSAEK (months)

\begin{tabular}{lll}
\hline DSAEK & ----- & $\begin{array}{l}\text { DSAEK + cataract extraction or } \\
\text { intraocular lens implantation }\end{array}$ \\
\hline$-\cdot-\cdot-\cdot-\cdot \cdot$ DSAEK + goniosynechiolysis &
\end{tabular}

Figure 2 (Continued) 


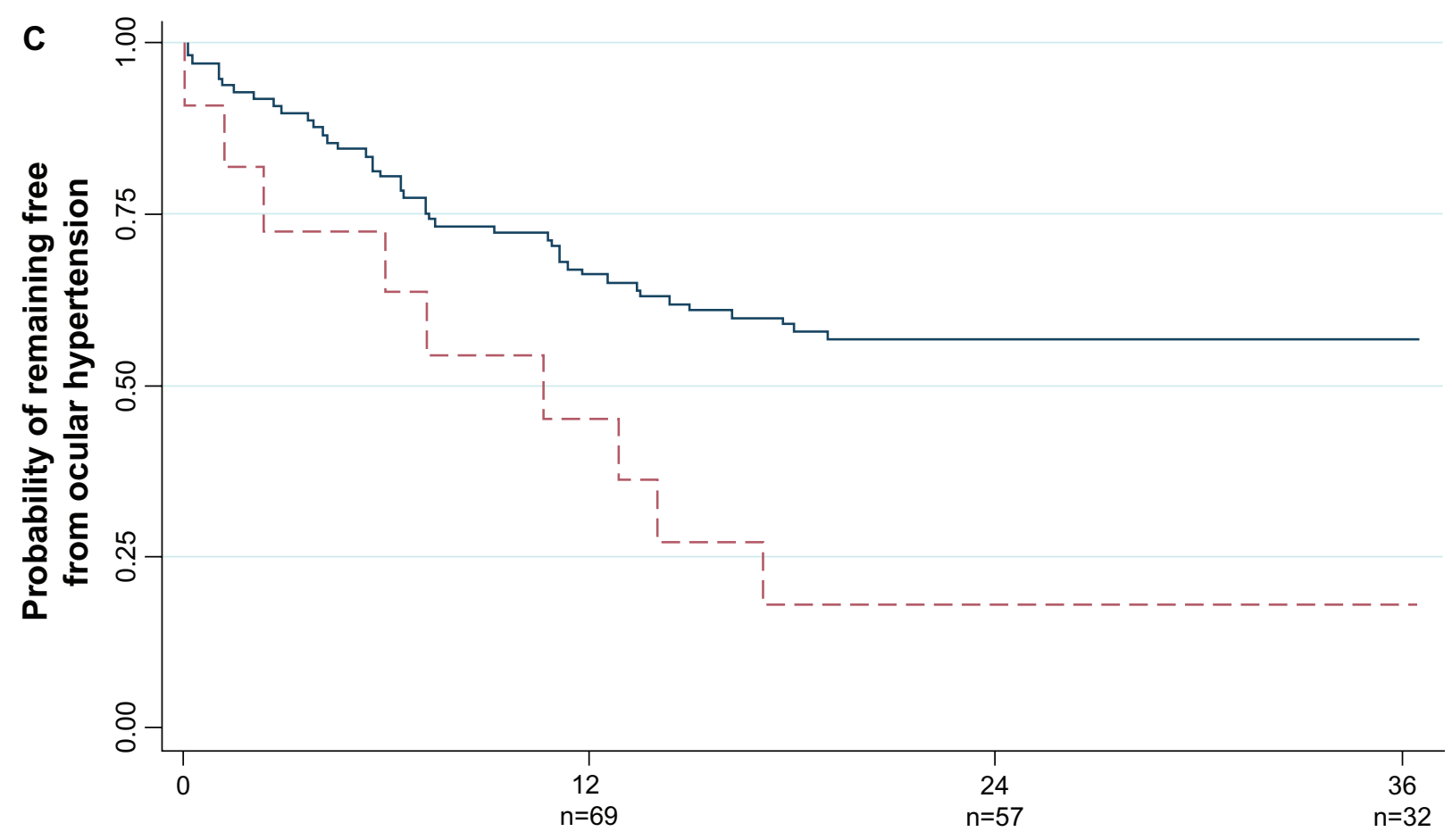

Time after DSAEK (months)

\begin{tabular}{|ll|}
\hline$-----\begin{array}{l}\text { Postoperative procedures } \\
\text { or complications }\end{array}$ & $\begin{array}{l}\text { No postoperative procedures } \\
\text { or complications }\end{array}$ \\
\hline
\end{tabular}

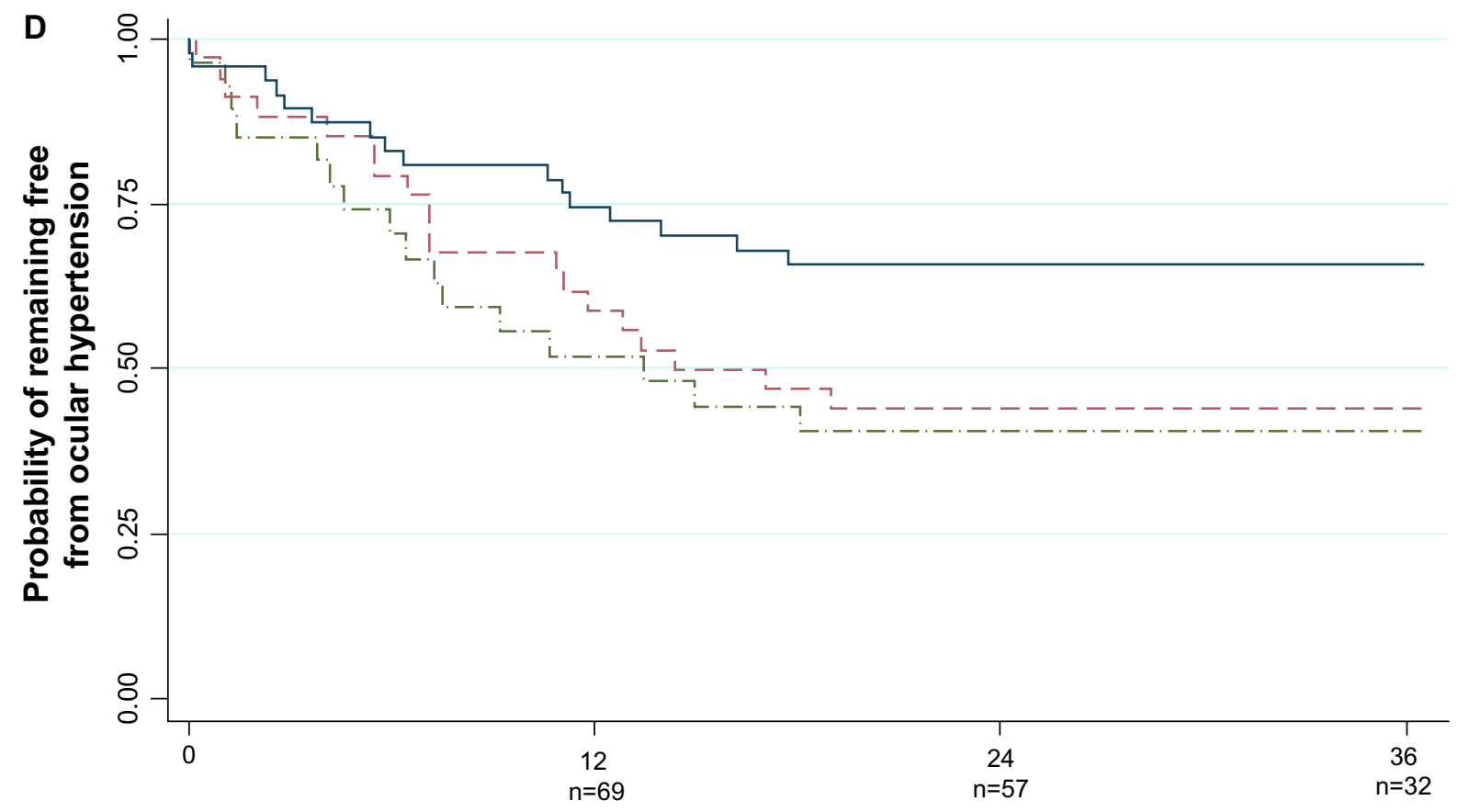

Time after DSAEK (months)

\begin{tabular}{rl|}
$---\cdot \cdot \cdot$ Age $<60$ & $-----60 \leq$ Age $<70$ \\
Age $\geq 60$ &
\end{tabular}

Figure 2 Kaplan-Meier survival curve showing probability of remaining ocular hypertension-free following Descemet stripping automated endothelial keratoplasty: (A) by fellow eye glaucoma status; (B) by concurrent procedures; (C) by postoperative complications and procedures; and (D) by age.

Abbreviation: DSAEK, Descemet stripping automated endothelial keratoplasty. 
Table 4 Two year outcomes after onset of de novo postDescemet stripping automated endothelial keratoplasty ocular hypertension: glaucoma filtration surgery requirement, IOP success, graft failure, and BSCVA

\begin{tabular}{|c|c|}
\hline & $\begin{array}{l}\text { DSAEK with post-graft } \\
\text { ocular hypertension }(n=51) \\
n(\%)\end{array}$ \\
\hline $\begin{array}{l}\text { Failure of medical therapy, ie, glaucoma } \\
\text { filtration surgery (Mitomycin-C } \\
\text { augmented trabeculectomy) } \\
\text { JOP success }\end{array}$ & $15(29.4)$ \\
\hline $\begin{array}{l}\text { Qualified (IOP }<22 \text { with topical } \\
\text { glaucoma medications) }\end{array}$ & $39(76.5)$ \\
\hline $\begin{array}{l}\text { Complete (IOP }<22 \text { without topical } \\
\text { glaucoma medications) }\end{array}$ & $12(23.5)$ \\
\hline Failure $(I O P \geq 22)$ & $0(0.0)$ \\
\hline Final IOP in mmHg & $17.8 \pm 9.4$ \\
\hline BSCVA $20 / 40$ or better & \\
\hline 6 months & $44(86.3)$ \\
\hline I-year & $45(88.3)$ \\
\hline 2 years & $47(92.1)$ \\
\hline DSAEK endothelial failure & $5(9.8)$ \\
\hline DSAEK rejection & $3(5.9)$ \\
\hline
\end{tabular}

Abbreviations: BSCVA, best-spectacle correct visual acuity; DSAEK, Descemet stripping automated endothelial keratoplasty; IOP, intraocular pressure.

\section{Discussion}

To date, comparing glaucoma or OHT rates between DSAEK and PK has been difficult because of heterogeneity in case definitions, follow-up duration, steroid regime, and inclusion criteria. This is the first study comparing intermediate-term incidence of post-DSAEK and post-PK OHT. At 3 years, $47.2 \%$ of DSAEK grafts developed OHT, which was not statistically different from $46.3 \%$ of PK grafts managed on the same steroid regimen. Systematic analysis of the impact of various clinical characteristics (eg, differences in corneal thickness) did not reveal differences in OHT rates between the two graft cohorts. This study is also the first to show that OHT development plateaus out in the second year, with none to minimal cases in the third year. Several clinical factors were linked with OHT after DSAEK, which could assist in risk prognostication. Although 29.7\% failed glaucoma medical therapy, $100 \%$ achieved either qualified or complete IOP success with glaucoma medications and/or surgery. OHT did not compromise graft outcomes, as $92.1 \%$ achieved BSCVA $\geq 20 / 40$, graft survival was $90.2 \%$, and $94.1 \%$ remained rejection-free. Collectively, these findings still support DSAEK as the preferred surgical strategy for endothelial decompensation, taking into consideration the need for close IOP monitoring and treatment.

OHT is a significant DSAEK complication. Wandling et al reported comparable rates of "glaucoma therapy escalation" using a different definition in a smaller cohort (34 DSAEKs, $20 \mathrm{PKs}, 41.2 \%$ versus $35 \%$ ), but did not adjust for differences in multiple clinical variables, including surgical indication, pre-existing glaucoma status, pachymetry, and follow-up duration. ${ }^{16}$ Our findings add to evidence of DSAEK/PK comparability in key graft outcomes, ie, graft failure, ${ }^{17-19}$ 3- and 5-year endothelial cell loss, ${ }^{17,18}$ although DSAEK is clearly superior for visual and tectonic outcomes. Indeed, OHT is the most frequent DSAEK complication, higher than graft dislocation ( $2 \%$ to $31 \%$ ), ${ }^{20-22}$ rejection ( $6 \%$ to $7.6 \%$ at 1 -year, and $12 \%$ to $14 \%$ at 2 years), ${ }^{23,24}$ and endothelial failure ( $24 \%$ for PBK and $5 \%$ for FED at 5 years). ${ }^{18}$ In our study, the 1-year OHT incidence was $36.2 \%$, comparable with $35 \%$ reported by Vajaranant et al using the same definition of preexisting glaucoma and $\mathrm{OHT}^{6}{ }^{6}$ Allen et al reported a 51\% OHT incidence, but included cases with and without pre-existing glaucoma. ${ }^{7}$ An earlier report from the American Academy of Ophthalmology (AAO) summarizing the DSAEK literature through 2009, concluded that "glaucoma" following DSAEK varied between $0 \%$ to $15 \%$ from 23 studies with 3 to 18 months of follow-up. ${ }^{25}$ The "glaucoma" definition was solely elevated intraocular pressure, ie, OHT. The lower OHT rates were likely due to shorter follow-up.

Understanding of post-DSAEK OHT has evolved over the last 5 years. Initial studies attributed IOP elevations to pupil-block by air migration behind the iris, ${ }^{3,25}$ however this has been eliminated with routine iridectomies. Vajaranant et al proposed steroid response as a causative factor, based on $30 \%$ having IOP elevation $>10 \mathrm{mmHg}$ above baseline, and IOP peaking at 3 months. ${ }^{6}$ The current study provides further evidence, based on leveling off in OHT incidence in the second year (consistent with once-daily steroid dosing by the first post-DSAEK year), and increased risk in younger recipients. The clinical implications are twofold. First, the dose and potency of steroids that allows appropriate trade-offs between OHT risk and rejection needs to be considered by ophthalmologists. Second, Descemet membrane endothelial keratoplasty (DMEK) may be increasingly important, because its lower risk of graft rejection may allow less reliance on post-graft steroids, ${ }^{26}$ possibly conferring a significantly lower risk of OHT.

Although steroid response is the main cause for OHT, four additional factors predict OHT risk, furthering our understanding of OHT after DSAEK. Peripheral anterior synechia, PBK, tight and long sutures, relatively undersized donor grafts, smaller recipient corneas, concurrent surgeries, and pre-existing glaucoma, are well-recognized risk factors for post-PK OHT., ${ }^{4,27}$ One study found 
that pre-existing glaucoma predicts IOP elevation after DSAEK, ${ }^{7}$ however other risk factors are unknown. In our study, OHT risk was increased 3.3, 2.9, 2.4, and 3.2 times in eyes with goniosynechiolysis, postoperative procedures and complications, age $<60$ years, and fellow eye glaucoma, respectively. Requirement for goniosynechiolysis may reflect more severe angle closure and compromised trabecular outflow with a propensity for OHT development. Postoperative procedures and complications (eg, ocular infections, retinal detachment, yttrium aluminum garnet [YAG] capsulotomies) expectedly result in increased intraocular inflammation, which could reduce trabecular function over time, as has been observed for PK. ${ }^{27-29}$ The tendency towards steroid-responsiveness in younger adults is consistent with the well-recognized risk of IOP elevation in this age group with topical or intravitreal steroids. ${ }^{30-32}$ It is not clear how glaucoma in the fellow eye influences OHT risk, but this may be a surrogate for trabecular function in the grafted eye. OHT risk after DSAEK was not influenced by surgical indication, unlike in PK. ${ }^{27,28}$ These four factors contributed a modest $23 \%$ to variability in OHT risk, with $77 \%$ possibly accounted for by differential steroid response susceptibility. Thus, IOP monitoring could be indicated for all eyes at 1, 3, and 6 months, and 6-monthly thereafter within the first three post-graft years in average-risk eyes, in line with recommendations for corticosteroid therapy. ${ }^{33}$ For eyes with high-risk characteristics, 3-monthly follow-up up to 3 years may be required.

Over 2 years from OHT onset, almost $30 \%$ of DSAEK eyes failed medical therapy and required trabeculectomy. In contrast, only $8.6 \%$ required glaucoma surgery in an earlier study. ${ }^{6}$ This difference was likely due to continuation of highpotency steroids in $94.2 \%$ (compared to $62.8 \%$ ) instead of switching to lower-potency agents. This practice was based on evidence that graft rejection is a major cause for graft failure in eyes at our center, ${ }^{12}$ and steroid reduction results in endothelial rejection. ${ }^{19,23,24}$ The high rate of glaucoma surgical escalation in this study approaches figures reported for intravitreal steroid implants (ie, >35\%). ${ }^{34}$ Nevertheless, glaucoma therapy was effective, such that all eyes achieved qualified or complete IOP success $<21 \mathrm{mmHg}$ at 2 years. These findings are consistent with an earlier report on the efficacy of filtration surgery in DSAEK in eyes with or without glaucoma, which could have a comparative advantage for DSAEK versus PK eyes. ${ }^{35}$

DSAEK eyes with OHT had comparable BSCVA, graft failure, and graft rejection as other published reports. Post-hoc analyses showed that OHT was not associated with these outcomes. In our study, $92.1 \%$ of DSAEK eyes with OHT achieved BSCVA of 20/40 or better. Using similar DSAEK techniques, BSCVA ranged between 20/34 to 20/66 at about 9 months (range 3-21 months); ${ }^{25}$ other authors reported BSCVA 20/40 or better in $92 \%$ at 6 months $^{36}$ and $98.1 \%$ at 3 years. ${ }^{37}$ OHT rarely leads to compromised shortterm visual outcomes, if IOP control has been achieved and central visual field damage has not developed. Graft rejection occurred in only $5.9 \%$ at 2 years post-OHT, which is within the range of reported rejection rates, if not more favorable, than in other recent cohorts $(11 \%-14 \% \text { at } 2 \text { years) })^{23,24}$ No studies have concluded that OHT or steroid response independently lead to DSAEK rejection, but steroid taper regardless of indication, is the major cause for rejection. ${ }^{23,24}$ Likewise, endothelial failure rate of $9.8 \%$ in this study is compatible with $4 \%$ to $14 \% 3$-year ${ }^{17}$ and $7 \%$ to $27 \% 5$-year ${ }^{18}$ rates for FED and PBK. Interestingly, Anshu et al reported that glaucoma surgery, in particular drainage implants, increases the 5 -year risk for graft failure, however this was not observed in our study. This could be due to shorter follow-up, and that all eyes received trabeculectomy instead of drainage implants, resulting in less endothelial attrition. ${ }^{38}$

Strengths include the prospective data in SCTS, $>96 \%$ who completed 3-year follow-up, and standardization of steroid regime and indication for glaucoma surgery. The conclusions on comparable OHT risk are valid as major clinical variables (importantly pre- and post-graft pachymetry) were comparable, and possible interactions between all variables with graft type were assessed and found to be absent. The analysis was repeated in eyes with clear grafts and GATmeasured IOPs to ensure uniformity of IOP measurements. Nevertheless, IOP differences in DSAEK and PK corneas based on different instruments or corneal thickness are generally not clinically significant. ${ }^{39-42}$

A limitation is the non-randomized design; however randomization would be unethical. The slightly earlier inclusion period for PK could have introduced temporal bias, although this is inherent in any DSAEK/PK comparative study, ${ }^{17,18}$ and grafts from largely comparable time periods were included. As graft failures were censored in the survival analysis, OHT development could not be observed after graft failure. However, such cases comprised the minority; $>90 \%$ DSAEK and PK eyes completed 3-year follow-up without censure.

In summary, this study of 324 DSAEK and PK procedures found no statistical difference in 3-year post-graft OHT incidence. Although a significant $30 \%$ of DSAEK eyes with OHT required filtration surgery, acceptable IOP and graft 
outcomes were achieved in these eyes. Age $<60$ years, fellow eye glaucoma, concurrent goniosynechiolysis, and postoperative complications and procedures prognosticate higher OHT risk and may be important considerations in post-graft management. Longer-term prospective studies are warranted to confirm these findings.

\section{Disclosure}

The authors report no conflicts of interest in this work.

\section{References}

1. Price MO, Price WP. Descemet's stripping endothelial keratoplasty. Curr Opin Ophthalmol. 2007;18(4):290-294.

2. Bahar I, Kaiserman I, McAllum P, Slomovic A, Rootman D. Comparison of posterior lamellar keratoplasty techniques to penetrating keratoplasty. Ophthalmology. 2008;115(9):1525-1533.

3. Koenig SB, Covert DJ. Early results of small-incision Descemet's stripping and automated endothelial keratoplasty. Ophthalmology. 2007;114(2):221-226.

4. Brandt JD, Lim MC, O'Day DG. Glaucoma After Penetrating Keratoplasty. In: Krachmer JH, Mannis MJ, Holland EJ, editors. Cornea. 2nd ed. Vol 2. Philadelphia: Elsevier Mosby; 2005:1575-1579.

5. Price MO, Thompson RW, Price FW. Risk factors for various causes of failure in initial corneal grafts. Arch Ophthalmol. 2003;121(8) 1087-1092.

6. Vajaranant TS, Price MO, Price FW, Gao W, Wilensky JT, Edward DP. Visual acuity and intraocular pressure after Descemet's stripping endothelial keratoplasty in eyes with and without preexisting glaucoma. Ophthalmology. 2009;116(9):1644-1650.

7. Allen MB, Lieu P, Mootha VV, et al. Risk factors for intraocular pressure elevation after descemet stripping automated endothelial keratoplasty. Eye Contact Lens. 2010;36(4):223-227.

8. Wiaux C, Baghdasaryan E, Lee OL, et al. Outcomes after Descemet stripping endothelial keratoplasty in glaucoma patients with previous trabeculectomy and tube shunt implantation. Cornea. 2011;30(12) 1304-1311.

9. Phillips PM, Terry MA, Shamie N, et al. Descemet stripping automated endothelial keratoplasty in eyes with previous trabeculectomy and tube shunt procedures: intraoperative and early postoperative complications. Cornea. 2010;29(5):534-540.

10. Kim P, Amiran MD, Lichtinger A, Yeung SN, Slomovic AR, Rootman DS. Outcomes of Descemet stripping automated endothelial keratoplasty in patients with previous glaucoma drainage device insertion. Cornea. 2012;31(2):172-175.

11. Quek DT, Wong T, Tan D, Mehta JS. Corneal graft survival and intraocular pressure control after descemet stripping automated endothelial keratoplasty in eyes with pre-existing glaucoma. Am J Ophthalmol. 2011;152(1):48-54. e2.

12. Tan DT, Janardhanan P, Zhou H, et al. Penetrating keratoplasty in Asian eyes: the Singapore Corneal Transplant Study. Ophthalmology. 2008;115(6):975-982. e1

13. European Glaucoma Society. Terminology and Guidelines for Glaucoma. 3rd ed. City: Dogma; 2008.

14. Mehta JS, Hantera MM, Tan DT. Modified air-assisted descemetorhexis for Descemet-stripping automated endothelial keratoplasty. J Cataract Refract Surg. 2008;34(6):889-891.

15. Mehta JS, Por YM, Poh R, Beuerman RW, Tan D. Comparison of donor insertion techniques for descemet stripping automated endothelial keratoplasty. Arch Ophthalmol. 2008;126(10):1383-1388.

16. Wandling GR, Rauen MP, Goins KM, et al. Glaucoma therapy escalation in eyes with pseudophakic corneal edema after penetrating keratoplasty and Descemet's stripping automated endothelial keratoplasty. Int Ophthalmol. 2012;32(1):9-14.
17. Ang M, Mehta JS, Lim F, Bose S, Htoon HM, Tan D. Endothelial cell loss and graft survival after Descemet's stripping automated endothelial keratoplasty and penetrating keratoplasty. Ophthalmology. 2012;119(11):2239-2244.

18. Price MO, Gorovoy M, Price FW, Benetz BA, Menegay HJ, Lass JH. Descemet's stripping automated endothelial keratoplasty: threeyear graft and endothelial cell survival compared with penetrating keratoplasty. Ophthalmology. 2013;120(2):246-251.

19. Price MO, Fairchild KM, Price DA, Price FW. Descemet's stripping endothelial keratoplasty five-year graft survival and endothelial cell loss. Ophthalmology. 2011;118(4):725-729.

20. Goshe JM, Terry MA, Li JY, Straiko MD, Davis-Boozer D. Graft dislocation and hypotony after Descemet's stripping automated endothelial keratoplasty in patients with previous glaucoma surgery. Ophthalmology. 2012;119(6):1130-1133.

21. Jangi AA, Ritterband DC, Wu EI, Mehta VV, Koplin RS, Seedor JA. Descemet stripping automated endothelial keratoplasty after failed penetrating keratoplasty. Cornea. 2012;31(10):1148-1153.

22. Clements JL, Bouchard CS, Lee WB, et al. Retrospective review of graft dislocation rate associated with descemet stripping automated endothelial keratoplasty after primary failed penetrating keratoplasty. Cornea. 2011;30(4):414-418.

23. Price MO, Jordan CS, Moore G, Price FW. Graft rejection episodes after Descemet stripping with endothelial keratoplasty: part two: the statistical analysis of probability and risk factors. $\mathrm{Br} J$ Ophthalmol. 2009;93(3):391-395.

24. Wu EI, Ritterband DC, Yu G, Shields RA, Seedor JA. Graft rejection following descemet stripping automated endothelial keratoplasty: features, risk factors, and outcomes. Am J Ophthalmol. 2012;153(5):949-957. e1.

25. Lee WB, Jacobs DS, Musch DC, Kaufman SC, Reinhart WJ, Shtein RM Descemet's stripping endothelial keratoplasty: safety and outcomes: a report by the American Academy of Ophthalmology. Ophthalmology. 2009;116(9):1818-1830.

26. Anshu A, Price MO, Price FW. Risk of corneal transplant rejection significantly reduced with Descemet's membrane endothelial keratoplasty. Ophthalmology. 2012;119(3):536-540.

27. Karadag O, Kugu S, Erdogan G, Kandemir B, Eraslan Ozdil S, Dogan OK. Incidence of and risk factors for increased intraocular pressure after penetrating keratoplasty. Cornea. 2010;29(3):278-282.

28. Al-Mohaimeed M, Al-Shahwan S, Al-Torbak A, Wagoner MD Escalation of glaucoma therapy after penetrating keratoplasty. Ophthalmology. 2007;114(12):2281-2286.

29. Oruçoglu F, Blumenthal EZ, Frucht-Pery J, Solomon A. Risk Factors and Incidence of Ocular Hypertension After Penetrating Keratoplasty. J Glaucoma. 2013.

30. Chang DF, Tan JJ, Tripodis Y. Risk factors for steroid response among cataract patients. J Cataract Refract Surg. 2011;37(4):675-681.

31. Jonas JB, Degenring RF, Kreissig I, Akkoyun I, Kamppeter BA. Intraocular pressure elevation after intravitreal triamcinolone acetonide injection. Ophthalmology. 2005;112(4):593-598.

32. Shukla D, Vidhya N, Prasad NM, Mahalakshmi R, Kolluru C, Krishnadas R. Evaluation of patient age as a risk factor for intraocular pressure elevation after intravitreal triamcinolone. Am J Ophthalmol. 2007;144(3):453-454

33. Kersey JP, Broadway DC. Corticosteroid-induced glaucoma: a review of the literature. Eye (Lond). 2006;20(4):407-416.

34. Bollinger K, Kim J, Lowder CY, Kaiser PK, Smith SD. Intraocular pressure outcome of patients with fluocinolone acetonide intravitreal implant for noninfectious uveitis. Ophthalmology. 2011;118(10):1927-1931.

35. Boey PY, Mehta JS, Ho CL, Tan DT, Wong TT. Outcomes of trabeculectomy after descemet stripping automated endothelial keratoplasty: a comparison with penetrating keratoplasty. Am J Ophthalmol. 2012;153(6):1091-1098. e2.

36. Terry MA, Shamie N, Chen ES, Phillips PM, Hoar KL, Friend DJ. Precut tissue for Descemet's stripping automated endothelial keratoplasty: vision, astigmatism, and endothelial survival. Ophthalmology. 2009;116(2):248-256. 
37. Li JY, Terry MA, Goshe J, Davis-Boozer D, Shamie N. Three-year visual acuity outcomes after Descemet's stripping automated endothelial keratoplasty. Ophthalmology. 2012;119(6):1126-1129.

38. Anshu A, Price MO, Price FW. Descemet's stripping endothelial keratoplasty: long-term graft survival and risk factors for failure in eyes with preexisting glaucoma. Ophthalmology. 2012;119(10): 1982-1987.

39. Chou CY, Jordan CA, McGhee CN, Patel DV. Comparison of intraocular pressure measurement using 4 different instruments following penetrating keratoplasty. Am J Ophthalmol. 2012;153(3): 412-418.
40. Chang DT, Pantcheva MB, Noecker RJ. Corneal thickness and intraocular pressure in edematous corneas before and after Descemet stripping with automated endothelial keratoplasty. Cornea. 2010;29(10):1125-1130.

41. Vajaranant TS, Price MO, Price FW, Wilensky JT, Edward DP. Intraocular pressure measurements following Descemet stripping endothelial keratoplasty. Am J Ophthalmol. 2008;145(5):780-786.

42. Mawatari Y, Kobayashi A, Yokogawa H, Sugiyama K. Intraocular pressure after Descemet's stripping and non-Descemet's stripping automated endothelial keratoplasty. Jpn J Ophthalmol. 2011;55(2): 98-102. 


\section{Supplementary table}

Table SI Multivariate analysis of OHT as a risk factor for BSCVA, graft failure, and graft rejection outcomes in 108 DSAEK eyes at 3 years post-graft

\begin{tabular}{lllll}
\hline Outcome & Factors & $\begin{array}{l}\text { Adjusted } \\
\text { odds ratio }\end{array}$ & $\mathbf{9 5 \%} \mathbf{C l}$ & P-value \\
\hline $\begin{array}{llll}\text { BSCVA 20/40 } \\
\text { or better* }\end{array}$ & OHT & I.05 & $0.23,4.75$ & $0.95 \mathrm{I}$ \\
$\begin{array}{l}\text { Graft failure** } \\
\text { Graft rejection }^{\dagger}\end{array}$ & OHT & 0.57 & $0.12,2.76$ & 0.489 \\
\hline
\end{tabular}

Notes: *Adjusted for age, gender, ethnicity, surgical indication, graft thickness, concurrent procedures, post-operative complications, graft rejection, graft failure; **adjusted for age, gender, ethnicity, surgical indication, concurrent procedures, DSAEK graft diameter, surgical diagnosis, post-operative procedures and complications, graft rejection; †adjusted for age, gender, ethnicity, surgical indication, DSAEK or PK graft in fellow eye, concurrent procedures, DSAEK graft diameter, post-operative procedures and complications.

Abbreviations: BSCVA, best-spectacle corrected visual acuity; $\mathrm{Cl}$, confidence interval; DSAEK, Descemet stripping automated endothelial keratoplasty; OHT, ocular hypertension; PK, penetrating keratoplasty.

\section{Publish your work in this journal}

Clinical Ophthalmology is an international, peer-reviewed journal covering all subspecialties within ophthalmology. Key topics include: Optometry; Visual science; Pharmacology and drug therapy in eye diseases; Basic Sciences; Primary and Secondary eye care; Patient Safety and Quality of Care Improvements. This journal is indexed on

Submit your manuscript here: http://www.dovepress.com/clinical-ophthalmology-journal

\section{Dovepress}

PubMed Central and CAS, and is the official journal of The Society of Clinical Ophthalmology (SCO). The manuscript management system is completely online and includes a very quick and fair peer-review system, which is all easy to use. Visit http://www.dovepress.com/ testimonials.php to read real quotes from published authors. 